\title{
Major congenital anomalies at birth in Benghazi, Libyan Arab Jamahiriya, 1995
}

R. Singh' and O. Al-Sudanit

$$
\begin{aligned}
& \text { الشذوذات المِلقية الكبرى عند الميلاد في بنغازي، المجماهيرية العربية الليبية، } 1995
\end{aligned}
$$

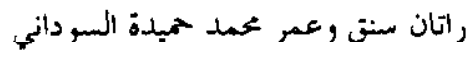

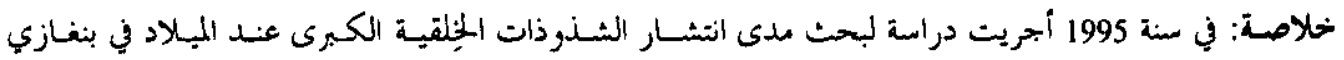

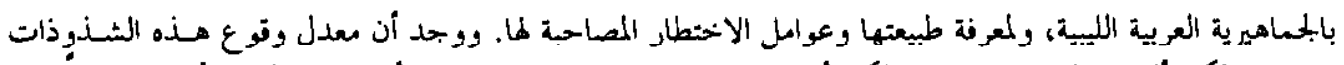

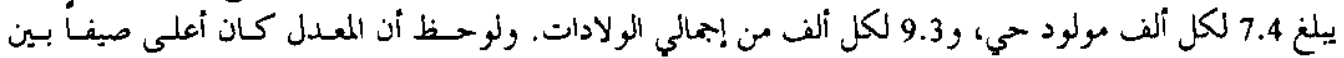

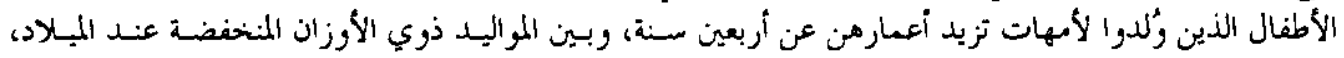

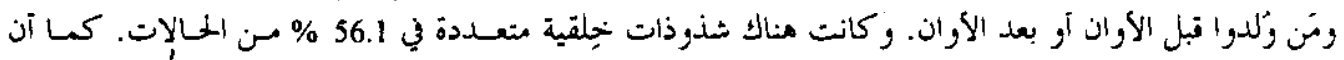

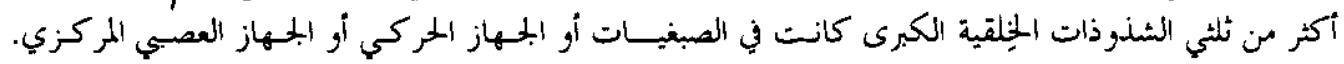

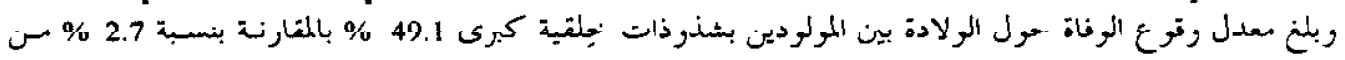

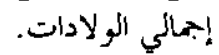

ABSTRACT A study was conducted to investigate the magnitude, nature and associated risk factors of major congenital anomalies (MCAs) at birth in Benghazi, Libyan Arab Jamahiriya in 1995. The incidence of MCAs was 7.4 per 1000 live births and 9.3 per 1000 total births. The rate was highor in summer, in babies born to mothors over 40 years and low-birth-woight babios or those born preterm or post-term. In $56.1 \%$ of cases there were multiple congenital anomalies and $>$ two-thirds of the major congenital anomalies were chromosomal, musculoskeletal or of the central nervous system. The incidence of perinatal death in births with MCAs was $49.1 \%$ compared with $2.7 \%$ for all births.

Les principales anomalies congénitales à la naissance à Benghazi (Libye)

RESUME Une étude visant a explorer l'ampleur, la nature et les facteurs de risque associes des principales anomalies congénitales à la naissance a été réalisée à Benghazi (Jamahiriya arabe libyenne) en 1995. L'incidence des principales anomalies congénitales était de 7,4 pour 1000 naissancos vivantos ot do 9,3 pour 1000 naissancos totalos. Le taux était plus élevé en été, chez les bébés dont la mère avait plus de 40 ans, chez les bébés de faible poids de naissance et ceux nés avant ou après terme. Dans $56,1 \%$ des cas, il y avait des anomalies multiples congénitales et plus des deux tiers des anomalies congénitales étaient chromosomiques, ostéo-articulaires ou des malformations du système nerveux central. L'incidence des décès périnatals était de $49,1 \%$ contre $2,7 \%$ pour l'ensemble des naissances.

'Faculty of Public Health, Al-Arab Medical University, Benghazi, Libyan Arab Jamahiriya. Recelved: 24/00/96; accepted: 22/11/90

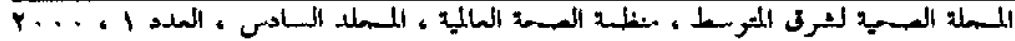




\section{Introduction}

Congenital anomalies (birth defects) arise at the time of conception or during intrauterine development and are present at birth. With the control of communicable diseases birth defects are being given more attention; especially with earlier diagnosis, improved management facilities and research work on their prevention $[1-12]$. The frequency of inherited and congenital anomalies varies widely, from $1 \%-10 \%$ of live births if all minor defects like haemangiomas, preauricular tags and other appendages are included $[1,5,7,12]$. Major congenital anomalies (MCAs) are now the leading cause of perinatal and infant morbidity and mortality in industrialized and developing countries, including the Libyan Arab Jamahiriya $[5,8,11-15]$.

There have been few epidemiological studies of congenital anomalies in the Libyan Arab Jamahiriya, although reports on individual cases have appeared in the literature [6,16-18]. A basic method for investigating birth defects is a review of hospital maternity records for all births. Such investigations can generate information on the magnitude of birth defects, their pattern and any associated risk factors which might have important implications for the generation of etiologic hypotheses and for planning or designing appropriate preventive, therapeutic and rehabilitative programmes.

Our study took place at Al-Jamahiriya Maternity Hospital, Benghazi and examined records for the year 1995 with the objective of investigating the magnitude, nature, determinants and hospital outcome of congenital anomalies.

\section{Subjects and methods}

Al-Jamahiriya Hospital is the main maternity hospital for the Benghazi municipality, the referral facility for the eastern region of the country and the teaching centre for AlArab Medical University and other health training institutes. Most births in the area took place at the hospital and were to Libyan nationals. The hospital made routine clinical examinations of all neonates for their general health, maturity and congenital anomalies. These examinations were carried out by the house surgeon attached to the neonatal intensive care unit (NICU) using a stethoscope, tongue depressor, torch and measuring tape. Those with identified risk factors or diagnosis of congenital malformations were further evaluated by a consultant paediatrician using ultrasonography and cytogenetic and biochemical investigation if required. All neonates identified with congenital anomalies were admitted to the NICU for observation, investigation. evaluation and management. Babies requiring more detailed investigations, advanced medical care or surgical interventions were transferred to Al-Fateh Paediatric Hospital or Al-Jila Surgical and Emergency Hospital.

Births with MCAs were defined, for the purpose of this study, as those which affected survival or caused structural, cosmetic or functional handicaps that required medical or surgical intervention. During 1995 there were a total of 16186 births, including 151 with MCAs. Data for all births with MCAs were analysed to identify risk factors and outcomes.

The sources of data included maternal records, registers from maternity and neonatal intensive care units, and certificates of stillbirths and early neonatal deaths filed at the hospital statistical unit. Except for hyperthyroid, the diagnosis of MCAs was based on routine clinical examination and in 1995 no autopsies or biochemical or cytogenetic investigations were carried out. Data analysed included information on ma-

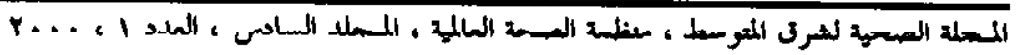


ternal variables, neonate characteristics, types of congenital anomalies and hospital outcome.

All births in the hospital over the same period were used as denominators to ascertain incidence rates, relative risk and hospital outcomes. The MCAs were classified according to the ICD-10 system and multiple MCAs were counted only once by the system of the most major anomaly [19].

\section{Results}

There were 15938 live births and 248 stillbirths at the hospital, of which 118 live births and 33 stillbirths had easily identifiable MCAs. Of the live births with MCAs. $110(93.2 \%)$ were born to Libyan parents and $105(89 \%)$ came from the Benghazi municipality.
There were 435 perinatal deaths ( 248 stillbirths and 187 early neonatal deaths) of which 58 were directly due to congenital malformation and their associated conditions or sequelae.

\section{Incidence rates}

The incidence rates for births with MCAs were 133.1,9.3 and 7.4 per 1000 stillbirths, total births and live births respectively (Table1) and $13.3 \%$ ( 58 out of 435 ) of hospital perinatal deaths were due to MCAs. Table 2 shows a comparison with incidence rates in a number of other countries.

The incidence rate varied throughout the year from 2.4 per 1000 live births in February to 12.9 in May. Quarterly it varied from a low of 5.6 per 1000 from Octoher to December to a high of 9.7 from April to June (Table 3)

Table 1 Births with major congenital anomalies (MCAs) and hospital perinatal mortality at Al-Jamahiriya Hospital, Benghazi, 1995

\begin{tabular}{|c|c|c|c|}
\hline Events & No. & $\begin{array}{l}\text { Incidence } \\
\text { per } 1000\end{array}$ & Denominator \\
\hline \multicolumn{4}{|l|}{ Births } \\
\hline All births & 16186 & N/A & \\
\hline With MCAs & 151 & 9.3 & All births \\
\hline \multicolumn{4}{|l|}{ Live births } \\
\hline All & 15938 & N/A & \\
\hline With MCAs & 118 & 7.4 & All live births \\
\hline \multicolumn{4}{|l|}{ Stillbirths } \\
\hline Al! & 248 & 15.3 & All births \\
\hline With MCAs & 33 & 133.1 & All stillbirths \\
\hline \multicolumn{4}{|l|}{ Early neonatal deaths } \\
\hline All & 187 & 11.7 & All live births \\
\hline With MCAs & 25 & 211.9 & Live births with MCAs \\
\hline \multicolumn{4}{|l|}{ Hospital perinatal deaths } \\
\hline Alt & 435 & 26.9 & All births \\
\hline With MCAs & 58 & 3.6 & All births \\
\hline Case fatality with MCAs & 58 & 384.1 & Births with MCAs \\
\hline
\end{tabular}




\begin{tabular}{|c|c|c|}
\hline \multirow[t]{2}{*}{ Location } & \multicolumn{2}{|c|}{ Incidence per 1000} \\
\hline & $\begin{array}{c}\text { Af } \\
\text { birthe }\end{array}$ & $\begin{array}{l}\text { Live } \\
\text { birthe }\end{array}$ \\
\hline Alexandria, Egypt [1] & - & 3.8 \\
\hline Bahrain, $1978[20]$ & 7.2 & 3.8 \\
\hline Bahrain, 1985 [20] & 18.5 & - \\
\hline Sweden [ 1$]$ & _ & 10.6 \\
\hline United Arab Emirates [7] & 21.6 & - \\
\hline Saudi Arabia [8] & - & 22.7 \\
\hline Kabul, Afghanistan [3] & - & 24.0 \\
\hline $\begin{array}{l}\text { Benghazi, Libyan Arab } \\
\text { Jamahirya (present study) }\end{array}$ & 9.3 & 7.0 \\
\hline
\end{tabular}

\section{Maternal oharaoteriotics}

MCAs per 1000 live births increased steadily from 6.6 for mothers of under 30 years to 27.6 for mothers of 40 years or more.

The incidence rate for live births with MCAs was 6.8 per 1000 for mothers who had borne four or fewer ehildren and increased to 8.6 per 1000 in those who had borne five or more. The proportion of neonates with chromosomal anomalics (compared to all MCAs) was higher among those born to mothers of 40 years or more or before 37 weeks of gestation and of higher parity (Table 4).

\section{Neonate characteristics}

The incidence rate of MCAs varied with gestational age from 6.5 per 1000 at full term (37-41 weeks) to 30.7 per 1000 below 37 weeks and 32.5 per 1000 at 42 weeks or more. The incidence rate was 7.8 per 1000 for males and 7.0 per 1000 for females (Table 4). For neonates with a birth weight of $2500 \mathrm{~g}$ or more, the incidence rate was 6.1 per 1000 and for those weighing $2500 \mathrm{~g}$ or less 38.5 per 1000 (Table 4).

\section{Number of anomalies}

The proportion of MCA births with single anomalies was $43.7 \%$ and multiple anomalies $56.3 \%$ (Table 5). Multiple anomalies were found in $57.6 \%$ of live births with MCAs in comparison with $51.5 \%$ of stillbirths.

\section{Categories of MCAs}

The congenital anomalies were classified by the systems involved according to the ICD-10 classification and multiple anomalies were counted only once based on the system involved in the most major malformation. Chromosomal anomalies were recorded on clinical evidence. The incidence rate was more than 2 per 1000 for chromosomal anomalies, anomalies of the central

Table 3 Live births with major congenital anomalles (MCAs) by months

\begin{tabular}{lccc}
\hline Months & All live births & $\begin{array}{c}\text { Live births } \\
\text { with MCAs }\end{array}$ & $\begin{array}{c}\text { No. MCAs } \\
\text { per 1000 live births }\end{array}$ \\
\hline January, February, March & 3979 & 29 & 7.29 \\
April, May, June & 3289 & 32 & 9.73 \\
July, August, September & 4231 & 32 & 7.56 \\
October, November, December & 4439 & 25 & 5.63 \\
Total & 15938 & 118 & 7.40 \\
\hline
\end{tabular}


Table 4 Live births with major congenital anomalies (MCAs) by maternal and infent varlables

\begin{tabular}{|c|c|c|c|c|}
\hline Variable & $\begin{array}{l}\text { All live } \\
\text { births }\end{array}$ & $\begin{array}{l}\text { Live births } \\
\text { with MCAs }\end{array}$ & $\begin{array}{l}\text { No. of MCAs per } \\
1000 \text { live births }\end{array}$ & $\begin{array}{c}\text { Relative } \\
\text { risk" }\end{array}$ \\
\hline \multicolumn{5}{|l|}{ Maternal variables } \\
\hline \multicolumn{5}{|l|}{ Age (years) } \\
\hline $\begin{array}{l}<30 \\
30-39\end{array}$ & $\begin{array}{l}9882 \\
5658\end{array}$ & $\begin{array}{l}65 \\
42\end{array}$ & $\begin{array}{l}6.6 \\
7.4\end{array}$ & $\begin{array}{l}0.89 \\
1.00\end{array}$ \\
\hline$\geq 40$ & 398 & 11 & 27.6 & 3.73 \\
\hline \multicolumn{5}{|l|}{ Parity } \\
\hline $0-4$ & 10847 & 74 & 6.8 & 0.92 \\
\hline$\geq 5$ & 5091 & 44 & 8.6 & 1.16 \\
\hline \multicolumn{5}{|l|}{ Infant variables } \\
\hline \multicolumn{5}{|l|}{ Sex } \\
\hline Male & 7790 & 61 & 7.8 & 1.05 \\
\hline Female & 8148 & 57 & 7.0 & 0.95 \\
\hline \multicolumn{5}{|c|}{ Gestational age (weeks) } \\
\hline Preterm $(<37)$ & 456 & 14 & 30.7 & 4.15 \\
\hline Full term $(37-41)$ & 15359 & 100 & 6.5 & 0.88 \\
\hline Post-term $(\geq 42)$ & 123 & 4 & 32.5 & 4.39 \\
\hline \multicolumn{5}{|l|}{ Birth weight (g) } \\
\hline $\begin{array}{l}<2500 \\
2500\end{array}$ & $\begin{array}{r}625 \\
15313\end{array}$ & $\begin{array}{l}24 \\
94\end{array}$ & $\begin{array}{r}38.5 \\
6.1\end{array}$ & $\begin{array}{l}5.20 \\
0.82\end{array}$ \\
\hline
\end{tabular}

-The relative risk was calculated from the overall rate of 7.4 per 1000 live births.

nervous system and musculoskeletal system. Together they accounted for $23.2 \%$, $23.8 \%$ and $22.5 \%$ of births with MCAs respectively (Table 6). The most common major congenital malformation was Down syndrome $(21.8 \%$ of all MCA births and $26.3 \%$ of live births with MCAs).

Tablo 5 Births with single or multiple major congenital anomalies (MCAs)

\begin{tabular}{lrrrrrrr}
\hline MCAs & \multicolumn{3}{c}{ Live births } & \multicolumn{3}{c}{ Stiltbirths } & \multicolumn{2}{c}{ Total births } \\
& No. & \multicolumn{1}{c}{$\%$} & No. & \multicolumn{1}{c}{$\%$} & \multicolumn{1}{c}{ No. } & \multicolumn{1}{c}{$\%$} \\
\hline Single & 50 & 42.4 & 16 & 48.5 & 66 & 43.7 \\
Multiple & 60 & 57.6 & 17 & 61.6 & 86 & 66.3 \\
Total & 118 & 100.0 & 33 & 100.0 & 151 & 100.0 \\
\hline
\end{tabular}

\section{Discussion}

Our results probably underestimate the number of congenital anomalies in Benghazi as a result of the lack of ultrasonography and a failure to conduct cytogenetic investigations or autopsies for stillbirths and neonatal deaths. However, as the hospital had used these criteria and procedures for diagnosis for the last 15 years, we expect that there was nearly complete recording of major, clinically identifiable anomalies of public health importance at birth or soon after.

The incidence rate of 9.3 per 1000 births and 7.4 per 1000 live births is within the broad range of reported MCAs worldwide $[1-12]$. MCAs at birth were higher 


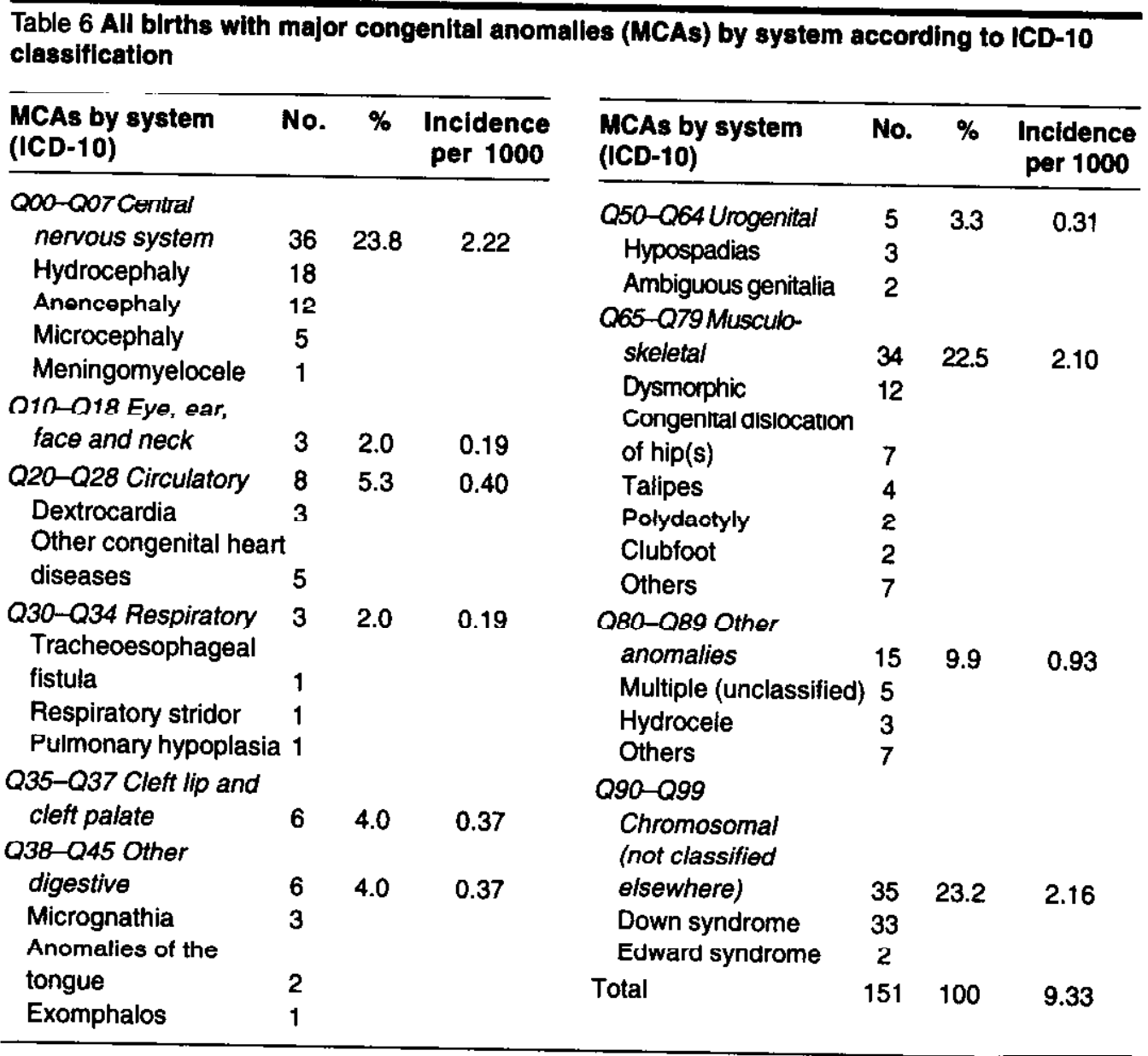

than figures reported from Alexandria (Egypt) and closer to those reported from Bahrain, Sweden and for the world as a whole $[1,2,4,12]$. However, the incidence rate was only one-half or one-third of that reported from Zaria (Nigeria), the Inited Arab Emirates (UAE), Saudi Arabia and Afghanistan $[1,3,7,8,12]$.

There have been considerable temporal, geographical and racial variations in the magnitude of congenital anomalies reported [4]. Longitudinal observations have shown fluctuations in the frequency of congenital anomalies over time $[4,21]$. For instance, congenital anomalies in Bahrain increased from 7.2 to 18.7 per 1000 live births between 1978 and 1985 [4] and anencephaly in Kuwait declined from $\mathbf{3 . 2}$ to 1.3 per 1000 births between the $1970 \mathrm{~s}$ and 1980s [21].

In Benghazi an earlicr reported MCA rate of 23.8 per 1000 live births included all minor as well as major congenital anomalies using an active prospective clinical and 
investigative search [6]. However, even the rate of 18.7 per 1000 observed for major MCAs is much higher than the incidence rate in our study. The reasons for such variation are not known but might be due to the retrospcetive cohort design of our study and the routine nature of the clinical detection of congenital anomalies. The authors of the earlier study, conducted between 1982 and 1984, actively screened for congenital anomalies using multiple, sophisticated, investigative techniques, such as ultrasonography, echocardiography, computed axial tomography and karyotyping extending into neonatal life via a paediatric follow-up clinic and inpatient ward [6]. Moreover, their findings remain unconfirmed by other independent authors. The two studies are also incomparable as our investigation included only major clinically identifiable congenital anomalies detected in routine maternity and paediatric practice. In addition, although unproven, changes in environmental, nutritional and lifestyle variables cannot be ruled out.

The incidence of MCAs by gender was almost equal and was in agreement with a similar observation from Saudi Arabia [8]. The influence of gender, if it exists, will require a larger study on populations from different parts of the country examining specific types of congenital anomalies.

Although the incidence rate of MCAs was generally higher during the summer and lower in winter, to look for any risk factors one would have to go back 6-9 months. Contrary to our results, the winter season has been documented elsewhere as having a higher incidence rate, (including in Benghazi), in particular for trisomy 21 $[6,22]$.

Neonates with a birth weight of less than the normal weight of $2500 \mathrm{~g}$ or more were five times more likely to have MCAs and preterm and post-term neonates four times more likely than those of normal (3741 weeks) gestational age. Similar values have been reported regarding birth weight for full term, live births in Saudi Arabia [8]. In Atlanta (USA), of 48 birth defect categories evaluated, 46 were found to be associated with intrauterine growth retardation [23]. The increased susceptibility of neonatcs born preterm or post-term could not be evaluated further because of inherent limitations in our secondary data.

The incidence of MCAs where mothers were 40 years or more was 3.5 times the overall rate. However, no obvious differences were observed by parity. Older maternal age and grand multiparity have been implicated elsewhere with higher occurrences of some birth defects [24]. In Saudi Arabia mothers of neonates with chromosomal malformations were found to be older and of greater parity than control groups [8].

In our study the proportion of caesarean section births among neonates with MCAs was $3.6 \%$ compared with an overall rate for the hospital of less than $0.6 \%$ [24]. Any link between the two conditions would need to be ascertained by a further, longitudinal study.

In our study, congenital anomalies of internal organs, and the circulatory system in particular, might have been underdetected due to nature of the secondary data. It is possible that some cases of congenital anomalies would have been undetected, particularly in asymptomatic neonates, in cases of internal anomalies and cases of perinatal death. It is unlikely, however, that any major, external or obvlous malformations were unrecorded.

Of 435 hospital perinatal deaths, $13.3 \%$ were due to MCAs and major anomalies were found in $49.1 \%$ of all births with congenital anomalies. Live births with congenital anomalies were found to have high 
rates of perinatal death in the UAE $(36 \%)$ and Saudi Arabia $(37 \%)[7,8]$. We observed fatality rates due to congenital anomalies close to those observed in the UAE and Saudi Arabia and higher than the $7.5 \%$ observed in Renghazi hetween 1982 and 1984 [6-8]. It is possible that this earlier lower rate was due to the inclusion in the hospital statistics of babies with minor defects and the exclusion of cases with more serious anomalies because of their rapid transfer to another hospital for paediatric medical or surgical treatment. Another alternative is the possibility of better environmental conditions and therefore a higher survival level during the previous study period.

According to ICD-10 classification of congenital anomalies, the systems involved in the MCAs recorded were (in descending order of frequency): central nervous system, ehromosomal (suspected on elinical grounds), musculoskeletal, other anomalies (cutaneous, unclassified multiple), digestive, circulatory, genitourinary, respiratory, and face and neck (including eye and ear). The first three categories were nearly equal in proportion $(22.5 \%-23.2 \%)$ and together formed more than two-thirds $(69.5 \%)$ of all births with MCAs. Clinically Down syndrome was the main chromosomal abcrration, with associated characteristic morphological features and concomitant disorders of multiple organ systems.

The earlier study in Benghazi reported that musculoskeletal disorders accounted for $34.4 \%$ of all birth defcets, followed by cardiovascular, chromosomal, digestive and cutaneous anomalies. In other countries the most common MCAs reported by system were: in Saudi Arabia, circulatory, musculoskeletal, central nervous, gastrointestinal and chromosomal; in the UAE, circulatory, musculoskeletal and cutaneous; and in Nigeria, musculoskeletal and central nervous system $[7,8,12]$. These re- ports indicate that our findings of high levels of musculoskeletal and central nervous system congenital anomalies are in line with observations from other countries.

The frequency of cardiovascular malformations was much lower than in the earlier study in Benghazi, probably because of a low level of clinical detection because of the lack of routine ultrasonography in the neonatal intensive care unit. Detection of congenital circulatory anomalies among stillbirths and carly nconatal deaths could not have been possible in the absence of autopsy practice in Benghazi. This might be one of the reasons why the rate of congenital heart disease in our study was low and conspicuously missing among the 33 stillbirths with MCAs.

Throughout the world chromosomal aberrations are among the least defined causes of congenital anomalies and cognitive defects. These disorders constitute a significant proportion of the genetic problems of the Eastem Mediterranean Region, giving rise to congenital abnormalities in about 5 per 1000 live births [4]. Chromosomal anomalies in general, and Down syndrome in particular, were among the most frequently reported anomalies in the study and earlier reports from Benghazi [6,25]. Moreover, the incidence of Down syndrome per 1000 live births in this study was 2.2 , which was higher than the earlier repurted rate of 1.7 per 1000 in Benghazi, 1.14 per 1000 in Bahrain, 1.8 per 1000 in Saudi Arabia and Egypt and 1.4 per 1000 worldwide $[4,6,8,20,26]$.

Although the consanguinity rate in this study was not known, the figure for parents of 500 consecutive Libyan children admitted to Al-Fateh Paediatric Hospital in Benghazl was earlier reported at $48.4 \%$ [27]. The traditional pattern of consanguineous marriage in Arab and Islamic countries, including the Libyan Arab Jamahiriya, 
may influence the incidence of congenital malformation as consanguinity has been shown to be associated with an incrcased prevalence of congenital anomalies $[19,28,29]$. It is reasonable to hypothesize that such a high consanguinity rate might have increased the frequency of autosomal recessive conditions in this population, although genetic data were not available for this study.

\section{Conclusion and}

\section{recommendations}

Our observed incidence rate of births with MCAs was moderate in comparison with global figures. More than two-thirds of the MCAs were of a central nervous, chromosomal or musculoskeletal nature. By individual anowalies, Down syndrome was the most frequent (present in more than $20 \%$ of all births with MCAs), followed by dysmorphic anomalies, hydrocephaly, anencephaly and congenital dislocation of the hip. Positively associated risk factors were high matemal age, preterm and post-term birth and low birth weight.

The proportion of births with chromosomal anomalies was higher in neonates born to mothers of high parity, over 40 years of age or very young mothers. Perinatal death in cases with MCAs was much higher than for all births.

Apart from the influence of advanced matcrnal age, (which was distinct in our study), the predisposing factors of non-disjunction of chromosomes resulting in trisomy 21 are poorly understood. The magnitude of chromosomal aberrations among the Libyan population in future, including Down syndrome, is likely to be influenced by, among other factors, prevailing age-specific fertility patterns. There is an urgent need for medical genetic studies and services, such as cytogenetic studies, syndrome identification and genetic counselling to enable proper etiologic diagnosis and the prevention of birth defects.

Despite some inherent limitations, this study provides basic information on the magnitude and spectrum of MCAs, some maternal and filial risk factors, the level of prenatial death associated with MCAs and the types of MCAs diagnosed at birth or soon afterwards. Therefore, larger crosssectional and prospective longitudinal epidemiological studies are urgently required on MCAs, both for Benghazi and the country as a whole. In addition, a national registration scheme for genetic disorders and congenital anomalies should be established. Randomized ctinical trials could be safely carried out at the community level on preventive measures; investigating and/or confirming the recently reported value of preconceptional and prenatal diet supplementation with multivitamins, folic acid and the vitamin A derivative, retinoic acid, found by other investigators to be essential for normal embryo genesis and protective against congenital anomalies $[10,11]$. It is estimated that using methods currently available, up to $60 \%$ of congenital anomalies are preventable [ 9 ]. However, these do not represent a single etiologic (pathological) category and will require multipronged, primordial population strategies and primary or secondary high-risk individual approaches for their prevention, which can be universally applied using the evidence available $[9,11]$.

Primary preventive programmes could be initiated now to reduce congenital malformations, particularly those related to higher maternal age, premature birth and low birth weight as well as secondary preventive measures to reduce excessive mortality, disability and dependency. There is an opportunity and a necessity to develop 
innovative health education strategies and to introduce standard screening and diagnostic procedures during the perinatal period. Moreover, it is imperative to develop high quality, cost-effective health care facilities and to create an effective support service of physical, educational, vocational and social rehabilitation for those babies surviving with impairments, disabilities and handicaps as a result of congenital birth defects.

\section{Acknowledgements}

We thank the Hospital Director, Dr Fatima Legnin of the Neonatal Intensive Care Unit and also the staff of the Records and Statistics Department for their generous cooperation, encouragement and advice. We also thank S.H. Najat, Z.S. Hoida, S.A. Salima, M. Amina and A.S. Eiman for their invaluable contribution in data collection during their internship training in research methodology in the Department of Family and Community Medicine.

\section{References}

1. Stevenson $\mathbf{A C}$ et al. Congenital malformations. A report of a study of series of consecutive births in 24 centres. Bulletin of the World Health Organization, 1996, 34(suppl.):9-27.

2. Kallen B, Winborg J. A Swodish rogister of congenital malformations. Experience with continuous registration during 2 years with special reference to multiple malformations. Pediatrics, 1968, 41:765-76.

3. Singh $\mathbf{M}$ ot al. Congenital malformations at birth among live-born infants in Afghanistan: a prospective study. Indian pediatrics. 1982, 49:331-5.

4. Hamamy $\mathbf{H}$, Alwan A. Hereditary disorders in the Eastern Mediterranean Region. Bulletin of the World Health Organization, 1994, 72(1):145-54.

5. Khoury M. Epidemiology of birth defects. Epidemiologic reviews, 1989, 11:1-24.

6. Mir NA, Galczek WC, Soni A. Early identifiable congenital malformations in children: survey of incidence and pattern in 32332 live-born neonates. Annals of Saudi medicine, 1992, 12(4):366-71.
7. Topley JM, Dawodu AH. The pattern of congenital anomalies among UAE nationals. Saudi medical journal, 1995 , 16(5):425-8.

8. Refat MYM et al. Major birth defects at King Fahd Hofuf Hospital: prevalence. risk factors and outcome. Annals of Saudi medicine, 1995, 15(4):339-43.

9. Czeizel AE, Intody Z, Modoll B. What proportion of congenital anomalies can be prevented? British medical journal, 1993, 306(6876):499-503.

10. Morriss-Kay GM, Sokolova N. Embryonic development and pattern formation. FASEB journal, 1996, 10(9):961-8.

11. Czeizel AE. Prevention of congenital anomalies by periconceptional multivitamin supplementation. British medical joumal, 1993, 306(6893):1645-8.

12. Ekanem $A D$, Chong $H$. Easily identifiable congenital malformations. British joumal of obstetrics and gynaecology, 1985, 92(suppt. 5):81-5.

13. Abudejaja A, Singh R, Khan MA. Trends and factors of infant mortality in Benghazi and the Libyan Jamahiriya. 
Garyounis medical journal, 1982 , $5(1): 37-46$.

14. Abudejaja A et al. Perinatal mortality at Benghazi, 1977. Garyounis medical journal, 1981, 4(2):15-25.

15. Singh $R$, Toweir A. Better intant health in Benghazi 1989. Libyan Jamahiriya. Garyounis medical journal, 1990, 13(1 and 2):7-15.

16. Mir NA et al. Facial clefting in Arab in fants. Annals of Saudi medicine, 1988, 8:206-8.

17. Mir NA et al. Musculoskeletal malformation in live-born neonates. Garyounis medical joumal, 1984, 7:165-8.

18. Kishan J, El-Zouki YA, Mir NA. Coarctation of aorta in the newborn: a clinical study. Annals of tropical paediatrics, $1984,4: 225-8$.

19. International statistical classification of diseases and related health problems (ICD-10), 10th rev. Geneva, Worlo Health Organization, 1992.

20. Arrayed SA et al. Congenital anomalios in Bahrain. Bahrain medical bulletin, 1987, 9:70-3.

21. Teebi AS. Autosomal recessive disorders among Arabs: an overview from Kuwait. Journal of medical genetics, 1994 , 31:224-33.
22. Leck I. Descriptive epidemiology of common malformations (excluding central nervous system defects). British medical bulletin, 1976, 32:45-52.

23. Khoury MJ et al. Congenital malformations and intrauterine growth retardation: a population study. Pediatrics, 1988, B2(1):83-8.

24. Ericson $\mathrm{A}$ et al. Socioeconomic variables and pregnancy outcome. II. Infant and child survival. Acta pediatrica Scandinavica, 1990, 79:1009-16.

25. Abudejaja A. Singh R, Legnain M. Reproductive experience of Libyan women at Benghazi. Garyounis medical journal, $1983,6(2): 173-80$.

26. Al-Najdi KN. Pattern of morbidity among hospital children. A one-year retrospective study. Journal af the Kuwait Modical Association, 1989, 23:158-62.

27. Broadhead RC, Sehgal KC. Consanguinity and congenital anomalies In East Libya. Garyounis medical journal, 1981, 4(1):3-6.

28. Young ID. Malformation in different ethnic groups. Archives of disease in childhood, 1987, 62:109-11.

29. El-Hazmi MAF, Warsy AS. Genetic disorders among Arab populations. Saudi medical journal, 1996, 17(2):108-29. 